\title{
ESTÁDIO DE MATURAÇÃO DOS FRUTOS E FATORES RELACIONADOS AOS ASPECTOS NUTRITIVOS E DE TEXTURA DA POLPA DE PEQUI (Caryocar brasiliense Camb.) ${ }^{1}$
}

\author{
MARIA NEUDES SOUSA DE OLIVEIRA², EDUARDO GUSMÃO ${ }^{3}$, PAULO SÉRGIO NASCIMENTO LOPES ${ }^{4}$, \\ MARIA OLÍVIA MERCADANTE SIMÕES ${ }^{5}$, LEONARDO MONTEIRO RIBEIRO ${ }^{6}$, BRUNA ANAIR SOUTO DIAS
}

RESUMO - O experimento foi conduzido com o objetivo de obter informações sobre a influência do estádio de desenvolvimento do fruto (época de coleta) e do tipo de congelamento sobre os componentes nutricionais e de textura da polpa de pequi (Caryocar brasiliense Camb.). Os frutos foram coletados na árvore, antes da queda natural; no chão, após a queda natural, e após a queda natural, mantidos três dias em condição ambiente. Em cada época de coleta, após a retirada da casca dos frutos, um grupo de putamens foi congelado diretamente em freezer, e outro, congelado em nitrogênio líquido, antes do congelamento em freezer. Após seis meses, foi retirada a polpa dos putamens para a análise dos teores de carotenóides totais, B -caroteno, licopeno, vitamina A, proteínas e lipídios; teor de celulose, hemicelulose, pectinas total, cálcio ligado à parede celular e total, atividade da pectinametilesterase e poligalacturonase. Os resultados indicaram que os teores de pigmentos, lipídios, proteínas e atividade da PG aumentaram com o avanço do estádio de maturação dos frutos. Por outro lado, houve diminuição no teor da celulose com avanço do estádio de maturação, enquanto os teores de hemicelulose e cálcio não foram influenciados pela idade do fruto. O tipo de congelamento interferiu nos teores de pigmentos, maiores na polpa congelada em nitrogênio líquido, e na atividade da PG, maior na polpa congelada apenas em freezer. Por último, os resultados mostraram que os frutos coletados na árvore são nutricionalmente inferiores aos coletados após a queda natural.

Termos adicionais para indexação: época de colheita, carotenóides totais, $\beta$-caroteno, licopeno, vitamina A, proteínas, lipídios, parede celular.

\section{MATURITY STAGE OF FRUITS AND FACTORS RELATED TO NUTRITIVE AND TEXTURE CHARACTERS OF PEQUI (Caryocar brasiliense Camb.) PULP}

\begin{abstract}
The experiment was carried out with the purpose to obtain information about changes in the constituents responsible for nutritive and texture traits of pequi pulp related with harvest time and types of freezing. Fruits were collected in the tree before natural fall, in the ground after natural fall and in the ground three days after natural fall. In each harvest time, while one batch of the putamens was frozen in liquid nitrogen and afterwards stored in a freezer, another batch was frozen directly in the freezer. After six months the following analyses were performed in the pulp: contents of proteins, total carotenoid, b-carotene, licopene, vitamin A and lipids (nutritive characters); content of cellulose, hemicelluloses, total pectin, total and bound calcium, activity of polygalacturonase (PG) and pectinmethilesterase (PME) of the cell wall. The contents of pigments, lipids, proteins and activity of PG were the highest in the most advanced stages of maturation of fruits. On the other hand the content of cellulose decreased with the advanced stages of maturation whiles the content of hemicelluloses, total and bound calcium were not affected at the stages of maturation of the fruits. The types of freezing affected the contents of pigments; higher in the pulp frozen in liquid nitrogen; and the activity of PG was higher in the pulp frozen directly in the freezer. The fruits collected in the tree showed the lowest eating quality as judged by their lowest contents of pigments, protein and lipids. The results indicate that the most appropriate harvest time to higher quality of pequi fruits is after natural fall.
\end{abstract}

Index Terms: harvest maturity, proteins, total carotenoid, b-carotene, licopene, vitamin A, lipids, cell wall.

\section{INTRODUÇÃO}

Os frutos do pequizeiro (Caryocar brasiliense Camb.) são muito ricos em óleo, proteínas e carotenóides. Ferreira et al. (1987) encontraram teores de óleo de $61,79 \%$ e $42,2 \%$ e teores de proteína de $6,71 \%$ e $24,6 \%$, respectivamente, na polpa e na amêndoa de frutos provenientes da região de Cerrado. O óleo é considerado de excelente qualidade, pois sua maior parte está constituída por ácidos graxos insaturados. A literatura apresenta teores elevados de carotenóides totais para o pequizeiro, $286,65 \mu \mathrm{g} / \mathrm{g}$ em polpa in natura (Ramos, 1987) e 231,09 e $154,06 \mu \mathrm{g} / \mathrm{g}$ em polpa crua e cozida, respectivamente (Ramos et al., 2001). Alguns autores apontam o fruto do pequizeiro como fonte potencial de vitamina A (Carvalho \& Burguer, 1960; Franco, 1982; Vilela, 1998), porém Azevedo-Meleiro \& Rodriguez-Amaya (2004) e Ramos et al. (2001), utilizando separação cromatográfica, identificaram que os principais carotenóides (anteraxantina, zeaxantina, violaxantina e luteína) do pequizeiro não possuem atividade pró-vitamina A, com o teor médio desta de 4.939
UI/100g (Ramos et al., 2001), muito inferior ao citado por Carvalho \& Burguer (1960), de $200.000 \mathrm{UI} / 100 \mathrm{~g}$. Apesar disso, os frutos de pequizeiro são uma importante fonte de vitamina $\mathrm{A}$, pois a quantidade diária exigida na dieta é de 4.500 U.I. (Carvalho \& Burger, 1960).

$\mathrm{O}$ amaciamento de frutos durante o seu amadurecimento implica modificações de polissacarídeos de parede celular (PC). Os reflexos econômicos desse amaciamento têm estimulado o desenvolvimento de uma série de pesquisas envolvendo o estudo das bases bioquímicas do metabolismo da PC durante o amadurecimento de frutos. A diminuição na firmeza (textura da polpa) durante o amadurecimento tem sido atribuída a modificações e à degradação dos componentes da parede celular, tais como celulose, hemiceluloses e pectinas. As substâncias pécticas constituem-se na classe de polissacarídeos da PC que sofrem a mais marcante modificação durante o amadurecimento de alguns frutos, com o aumento, solubilização e despolimerização associadas ao amolecimento dos frutos (Brumel \& Labavitch, 1997; Hadfield \& Bennett, 1998). A degradação de pectina geralmente é acompanhada

\footnotetext{
${ }^{1}$ (Trabalho 087-2005). Recebido: 20-05-2005. Aceito para publicação: 27-07-2006 (38)3531 1811 (mneudes@yahoo.com.br).

${ }^{3}$ Mestrando Fisiologia Vegetal. Universidade Federal de Viçosa.

${ }^{4}$ Profo $^{\circ}$. Universidade Federal de Minas Gerais - UFMG/NCA, 39400-000, Montes Claros, MG.

${ }^{5}$ Prof $^{\mathrm{a}}$. Dept ${ }^{\circ}$ Biologia Geral, Universidade Estadual de Montes Claros - UNIMONTES, 39410-089, Montes Claros, MG

${ }^{6}$ Prof $^{\mathrm{a}}$. Dept ${ }^{\circ}$ Biologia Geral, Universidade Estadual de Montes Claros - UNIMONTES, 39410-089, Montes Claros, MG. ${ }^{7}$ Aluna de Engenharia Florestal, UFVJM.
}

${ }^{2}$ Prof $^{\text {a }}$. Dept ${ }^{\circ}$. Ciências Básicas, Universidade Federal dos Vales do Jequitinhonha e Mucuri - UFVJM, Rua da Glória, 187, 39100-000, Diamantina, MG, 
por aumento na atividade de hidrolases da PC, tais como poligalacturonase (PG) e pectinametilesterase (PME) (Pimenta et al., 2000). Vários estudos relacionam a inibição da ativação da PG durante o amadurecimento com a extensão da sobrevivência e vida de prateleira do fruto.

O cálcio é um mineral importante na manutenção da estabilidade da PC em função da sua associação com as substâncias pécticas, ligando-se covalentemente às pectinas, dando origem ao pectato de cálcio, que restringe a ação da PME e PG e, consequientemente, retardando o amaciamento de frutos (Salunkhe et al., 1991). Pulverizações e imersões de frutos em soluções de cloreto de cálcio retardam seu amaciamento e senescência em função do aumento do cálcio ligado à PC (Scalon, 1996).

A qualidade dos frutos depende, além de outros fatores, do estádio de maturação por ocasião da colheita, o qual influencia muito na vida útil pós-colheita. Colheitas realizadas antes que os frutos atinjam completa maturação fisiológica, prejudicam o processo de amadurecimento, afetando a sua qualidade. Por outro lado, colheita de frutos totalmente maduros reduz a vida útil, dificulta o manuseio e transporte, devido sua baixa resistência física, causando perdas quantitativas e qualitativas (Chitarra \& Chitarra, 1990). Os frutos de pequi são normalmente coletados no chão, logo que amadurecem e caem das árvores, quando são considerados maduros. Após a queda natural, caso não seja realizada a coleta imediata, os frutos tornamse macios em dois ou três dias e rapidamente entram em processo de deterioração. Em função da crescente demanda e quando os preços são altos, muitos coletores realizam a coleta na árvore ("pequi de vara"), que consta da derrubada dos frutos sem que tenham completado o processo de maturação, considerado um dos principais problemas do extrativismo atual do pequi, reduzindo a qualidade do fruto comercializado. O congelamento na entressafra, um dos principais métodos de conservação de frutos, tem sido bastante utilizado na conservação de pequi. Durante a safra, os frutos são descascados, e os putamens (polpa ou mesocarpo interno + semente = caroço), acondicionados em saco plástico e conservados em freezer para o consumo na entressafra.

Objetivou-se, neste trabalho, verificar as modificações nos teores de carotenóides totais, ß-caroteno, licopeno, vitamina A, proteínas, lipídios, celulose, hemicelulose, pectina, cálcio ligado à parede e total, atividade da pectinametilesterase e poligalacturonase da polpa de pequi em frutos coletados em três estádios de maturação e submetidos a dois tipos de congelamento.

\section{MATERIAL E MÉTODOS}

Os frutos foram provenientes de uma área de Cerrado nativo do Centro de Agricultura Alternativa do Norte de Minas (CAA/ $\mathrm{NM}$ ), localizado a $30 \mathrm{~km}$ ao norte da cidade de Montes Claros - MG. Foram coletados, de oito árvores selecionadas ao acaso, entre 5 e 8 frutos/árvore em três estádios de desenvolvimento, buscando simular as diferentes épocas em que os frutos são coletados pelas populações rurais: coleta na árvore, antes da queda natural; coleta no chão, após a queda natural; coleta no chão após a queda natural e deixados por três dias em condição ambiente. A coleta na árvore simula o "pequi de vara", que consta da derrubada do fruto verde (frutos que não desprendiam da planta após balançar o galho). A coleta no chão após a queda natural é a forma normalmente utilizada, quando o fruto é considerado maduro. A coleta no chão, com frutos mantidos três dias em condição ambiente, simula o tempo normalmente utilizado da coleta ao consumo (transporte e comercialização).

Após cada coleta, a casca (mesocarpo externo + exocarpo) foi retirada, e os putamens (mesocarpo interno ou polpa + semente) passaram por desinfecção com hipoclorito de sódio $1 \%$, durante 5 minutos. Dentro de cada época de coleta, um grupo de putamens foi congelado em nitrogênio líquido, e posteriormente armazenado em freezer, e outro, congelado diretamente em freezer. Após seis meses, a polpa foi submetida às análises de parâmetros relacionados aos aspectos nutritivos (teores de carotenóides totais, $\beta$-caroteno, licopeno, vitamina A, proteínas, lipídios) e de textura (teor de celulose, hemicelulose, pectina total, cálcio ligado à parede e total, atividade da pectinametilesterase e poligalacturonase) da polpa.

Todas as análises foram realizadas no Laboratório de Bioquímica de Frutos do Departamento de Ciências dos Alimentos da Universidade Federal de Lavras, seguindo as seguintes metodologias: Teor de bcaroteno e licopeno: Nagata \& Yamashita (1992); Vitamina A, os dados de teores de $\beta$-caroteno foram transformados para serem expressos em vitamina $A$, utilizando a seguinte equação: Vitamina $A$ $=((\beta$-caroteno $\mathrm{mg} /(0,0006 * \beta$-caroteno $\mathrm{mg})) * 100$; Teor de lipídios, proteínas e carotenóides totais: AOAC (1965); Cálcio ligado (utilizando material de parede celular $=$ PC) e total: Sarruge \& Haag (1974); Celulose e hemicelulose: antrona (Dische, 1962); pectina total: Bitter \& Muir (1962); Extração da PG e PME: Pressey \& Avants (1969); Determinação da PG e PME: Nelson (1944) e Ratner et al. (1969), respectivamente. Uma unidade de atividade da PG é a quantidade de enzima capaz de catalisar a formação de um nmol de grupos redutores por minuto nas condições do ensaio. Uma unidade de atividade da PME é a quantidade de enzima capaz de catalisar a desmetilação de pectina correspondente ao consumo de um nmol de $\mathrm{NaOH}$. min $^{-1}$ nas condições do ensaio. Os resultados de atividade de enzimas foram expressos em unidade por grama de peso fresco (U/g), e os de celulose, hemicelulose, pectina e cálcio, em percentagem na parede celular.

$\mathrm{O}$ experimento seguiu um delineamento inteiramente casualizado, seguindo esquema fatorial $3 \times 2$ (estádio de desenvolvimento do fruto $\mathrm{x}$ tipo de congelamento), com três repetições. Cada repetição consistiu de uma porção de polpa obtida da mistura de polpa retirada dos frutos das 5-8 árvores. Para a interpretação dos resultados, realizou-se a análise de variância, e as médias dos tratamentos foram comparadas pelo teste de Tukey, a $5 \%$ de probabilidade.

\section{RESULTADOS E DISCUSSÃO}

Teor de proteína (Tabela 1)- Os teores de proteína na polpa variaram entre 3,54 e 4,04\%. Vilela (1998) encontrou teores de 4,9 e de 6,0\% em frutos coletados na mesma localidade do presente experimento e em Brasilândia-MG, respectivamente. Em frutos procedentes de outras regiões, Ferreira et al. (1987) obtiveram um valor de 1,61g/100g (Luiziânia-GO), Carvalho \& Burger (1960) constataram 2,65g/100g (Brasília-DF). Esses dados mostram a grande variabilidade que pode ser explorada em programas de melhoramento genético e a superioridade dos pequis de Minas Gerais quanto ao teor de proteína. Observando a tabela de composição química dos alimentos (Franco, 1982), vê-se que, dos frutos tropicais mais consumidos, o teor protéico da polpa do pequi só está abaixo do coco da Bahia, que apresenta um teor de $5,5 \mathrm{~g} / 100 \mathrm{~g}$. O teor de proteínas aumentou gradativamente com o grau de amadurecimento do fruto, mas foi significantemente superior $(\mathrm{p}<0,05)$ no tratamento em que os frutos foram mantidos por três dias em condição ambiente após a queda natural, e não foi influenciado pelo tipo de congelamento.

Teor de lipídios (Tabela 1) - O teor de lipídios não variou com o tipo de congelamento, mas diferiu com o estádio de desenvolvimento dos frutos; aumentou de $24,32 \%$ na polpa dos frutos coletados na planta, para $27,17 \%$ na polpa dos frutos mantidos três dias em condição ambiente após a queda natural. Analisando o teor de lipídios da polpa de pequi em dois estádios de maturação, Carvalho \& Burger (1960) observaram que o teor foi de 5,76g/100g nos frutos "de vez" e de $10 \mathrm{~g} / 100 \mathrm{~g}$, nos frutos maduros. Comparando-se os valores médios obtidos do presente trabalho com os obtidos por Vilela (1998), observa-se que ambos se equiparam, mas são superiores aos valores de $10 \mathrm{~g} / 100 \mathrm{~g}$ e $14,83 \mathrm{~g} / 100 \mathrm{~g}$ relatados por Carvalho \& Burger (1960) e 
Ferreira et al. (1987), em frutos coletados em Brasília-DF e LuiziâniaGO, respectivamente. Valores bem superiores, $32,55 \%$, foram observados por Ramos (1987), em frutos oriundos de Campo GrandeMS. Observando-se a tabela de composição química dos alimentos (Franco, 1982), constata-se que o teor de lipídios do pequi é comparável ao da macaúba, do babaçu e do abacate. Além disso, o óleo de pequi é considerado de excelente qualidade por ter sua maior parte constituída de ácidos graxos insaturados. Numa revisão sobre a composição de ácidos graxos da polpa de pequi, Araújo (1995) mostra que o ácido palmítico e oléico foram os mais representativos, com $39 \%$ e até $54 \%$, respectivamente, em relação aos ácidos graxos presentes. Segundo pesquisas da EMBRAPA/ CPAC, citadas por Araújo (1994), o óleo do pequi pode ser utilizado com sucesso na fabricação de cosméticos por sua clareza e delicado aroma, o que pode ser confirmado pelas recentes pesquisas desenvolvidas pelo Centro Tecnológico de Minas Gerais, que obteve um derivado do óleo com alta capacidade de ser absorvido pela pele, o que vem despertando o interesse da indústria farmacêutica (Alves, 2004).

Teores de carotenóides totais, $\boldsymbol{\beta}$-caroteno, licopeno e vitamina $\mathrm{A}$ (Tabela 2)- Os teores dos pigmentos analisados (carotenóides totais, $\beta$-caroteno e licopeno) apresentaram aumentos significativos $(\mathrm{p}<0,05)$ com o avanço no estádio de maturação dos frutos, concordando com as observações de Goldschmidt (1980) de que a síntese de carotenóides aumenta nas últimas fases de maturação dos frutos. Os teores de $\beta$-caroteno, licopeno e de carotenóides totais variaram, respectivamente, de 6,26 a 11,4; 1,12 a 2,08, e 6,75 a $11,34 \mathrm{mg}$ por $100 \mathrm{~g}$ de polpa. Os teores de $\beta$-caroteno estão na faixa dos encontrados em cenoura $(61,6 \mu \mathrm{g} / \mathrm{g})$ por Niizu \& Rodriguez Amaya (2004) e muito acima dos encontrados por Ramos et al. (2001), de 9,35 $\mu \mathrm{g} / \mathrm{g}$ de polpa. Apesar de, no presente estudo, os teores de $\beta$-caroteno representarem mais de $90 \%$ dos teores de carotenóides totais em todos os tratamentos, as análises de Azevedo-Meleiro \& Rodriguez-Amaya (2004) mostraram que os principais carotenóides do pequi são violanxantina, luteína e zeaxantina, com pequenas quantidades de $\beta$-criptoxantina, $\beta$-caroteno e neoxantina. Ramos et al. (2001) encontraram maiores teores de anteraxantina, zeaxantina, criptoflavina, seguidos de $\beta$-caroteno. Diferentemente dos demais trabalhos citados na literatura, Ramos et al. (2001) e Azevedo-Meleiro \& Rodriguez-Amaya (2004) utilizaram cromatografia como técnica de separação dos carotenóides. Em outra espécie do mesmo gênero (Caryocar villosium), Godoy (1993) determinou a zeaxantina como o carotenóide predominante, seguido de $\beta$-criptoxantina e $\beta$ caroteno.

Os teores de carotenóides totais estão aquém dos encontrados por Ramos (1987) e Ramos et al. (2001), que observaram, respectivamente, valores de 55,9 mg por 100 gramas de polpa e de $231,09 \mu \mathrm{g} / \mathrm{g}$ de polpa de frutos analisados imediatamente após a coleta, diferentemente do presente trabalho, em que a polpa foi analisada seis meses após o congelamento.
Nos frutos coletados no chão e mantidos três dias em condição ambiente, os maiores teores de $\beta$-caroteno e licopeno foram superiores naqueles congelados em nitrogênio líquido (congelamento rápido) antes de serem armazenados no freezer. Comparando-se os frutos coletados na planta com os coletados no chão, três dias após queda natural, o aumento nos teores de carotenóides totais, $\beta$-caroteno e licopeno foi de $40 \%, 30,4 \%$ e $24 \%$, respectivamente. Quando os frutos foram submetidos ao congelamento em nitrogênio líquido antes do acondicionamento em freezer, os aumentos nos teores de $\beta$-caroteno e licopeno foram de $45 \%$ e $46 \%$, respectivamente. Esses resultados mostram que o acúmulo de pigmentos continuou após a queda dos frutos e que o congelamento rápido proporcionou maior preservação nos teores de $\beta$-caroteno e licopeno, o que pode ser explicado pelo afirmado por Cheftel et al. (1989), de que, a $-18{ }^{\circ} \mathrm{C}$ (temperatura média do freezer), uma apreciável porção de água permanece no estado líquido, o que acelera as reações oxidativas no produto congelado. Alguns estudos citados por Ramos (1987) mostram que a presença de oxigênio é um fator crítico na degradação de carotenóides. Cavalcante (1991), avaliando a estabilidade dos carotenóides em pitanga após o congelamento lento (6h), observou que a estocagem por 30 dias acarretou perda significativa de $63 \%$ de $\beta$-caroteno. No presente trabalho, não foi avaliado o teor de pigmentos na polpa imediatamente após a coleta dos frutos, o que restringe a discussão dos dados ao tipo e não ao tempo de congelamento. Esse fato pode explicar a discrepância entre os teores de carotenóides totais obtidos no presente experimento, 6,75 a 11,34 mg/100g, e os observados por Ramos (1987), 55,9 mg/100g de polpa, e Ramos et al. (2001), 23,1 mg/ $100 \mathrm{~g}$ de polpa. Segundo Ramos (1987), a preservação dos carotenóides durante o processamento é um dos grandes desafios aos processadores de alimento, pois estes são compostos extremamente suscetíveis às reações oxidativas devido ao seu alto grau de insaturação. Sua estabilidade varia com a temperatura, oxigênio, luz, teor de umidade, $\mathrm{pH}$ e estrutura. $\mathrm{O}$ congelamento em nitrogênio líquido é recomendado na conservação dos carotenóides para análises laboratoriais posteriores (Vilela, 1998). Isso pode estar associado à menor porção de água que permanece no estado líquido, o que, segundo Cheftel et al. (1989), minimiza as reações oxidativas e poderia justificar os maiores valores observados nos teores de $\beta$ caroteno e licopeno na polpa de pequi, no tratamento em que os putamens foram congelados em nitrogênio líquido, antes do acondicionamento em freezer.

O amadurecimento de frutos é freqüentemente acompanhado pelo aumento da concentração de carotenóides e pelo aumento na proporção de carotenos para xantofilas. Segundo Ramos (1987), o $\alpha, \beta$ e o $\gamma$-caroteno e o licopeno são os mais comuns em frutos. A contribuição do licopeno na coloração da polpa de pequi pode ser confirmada pelos resultados do presente experimento, em que os valores deste pigmento chegaram a $2,08 \mathrm{mg} / 100 \mathrm{~g}(20,8 \mu \mathrm{g} / \mathrm{g})$ de polpa (Tabela 2). Estes valores não estão muito aquém dos $31,1 \mu \mathrm{g} / \mathrm{g}$

TABELA 1 - Estádio de maturação dos frutos de pequizeiro e teores de proteínas (\%) e lipídios (\%).

\begin{tabular}{|c|c|c|c|c|c|}
\hline \multirow{2}{*}{ Estádio de maturação dos frutos } & \multirow{2}{*}{$\begin{array}{c}\text { Parâmetros } \\
\text { avaliados } \\
\text { Tipo de } \\
\text { congelamento }\end{array}$} & \multicolumn{2}{|c|}{$\begin{array}{l}\text { Teor de proteínas } \\
\quad(\mathrm{CV}=\mathbf{3}, \mathbf{0 5} \%)\end{array}$} & \multicolumn{2}{|c|}{$\begin{array}{c}\text { Lipídios } \\
(\mathrm{CV}=\mathbf{3 , 0 5 \%})\end{array}$} \\
\hline & & Freezer & $\begin{array}{l}\text { N liq. + } \\
\text { freezer }\end{array}$ & Freezer & $\begin{array}{l}\text { N liq. + } \\
\text { freezer }\end{array}$ \\
\hline Coleta na árvore & & $\begin{array}{c}3,68 \\
\mathrm{Ba}\end{array}$ & $\begin{array}{c}3,54 \\
\mathrm{Ba}\end{array}$ & $\begin{array}{c}24,59 \\
\mathrm{Ba}\end{array}$ & $\begin{array}{c}24,32 \\
\mathrm{Ba}\end{array}$ \\
\hline $\begin{array}{l}\text { Coleta no chão } \\
\text { após queda natural }\end{array}$ & & $\begin{array}{c}3,76 \\
\mathrm{Ba}\end{array}$ & $\begin{array}{c}3,85 \\
\mathrm{Aa}\end{array}$ & $\begin{array}{c}26,07 \\
\mathrm{Aa}\end{array}$ & $\begin{array}{c}26,71 \\
\mathrm{Aa}\end{array}$ \\
\hline $\begin{array}{l}\text { Coleta após queda natural + } \\
\text { três dias em condição ambiente }\end{array}$ & & $\begin{array}{c}4,04 \\
\mathrm{Aa}\end{array}$ & $\begin{array}{c}3,98 \\
\mathrm{Aa}\end{array}$ & $\begin{array}{c}26,73 \\
\mathrm{Aa}\end{array}$ & $\begin{array}{c}27,17 \\
\mathrm{Aa}\end{array}$ \\
\hline
\end{tabular}

Médias seguidas pela mesma letra, maiúsculas nas colunas e minúsculas nas linhas, indicam que o estádio de maturação dos frutos e tipo de congelamento, respectivamente, não diferem estatisticamente, pelo teste de Tukey $(p<0,05)$. ( $N=$ nitrogênio). 
TABELA 2 - Estádio de maturação dos frutos de pequizeiro e teores de carotenóides totais (mg/100g), $\beta$-caroteno (mg/100g), licopeno (mg/ 100 g) e vitamina A(U.I. x 1000).

\begin{tabular}{|c|c|c|c|c|c|c|c|c|c|}
\hline \multirow{2}{*}{$\begin{array}{l}\text { Estádio de } \\
\text { maturação } \\
\text { dos frutos }\end{array}$} & \multirow{2}{*}{$\begin{array}{l}\text { Parâmetros } \\
\text { avaliados } \\
\text { Tipo de } \\
\text { congelamento }\end{array}$} & \multicolumn{2}{|c|}{$\begin{array}{c}\text { Carotenóides } \\
\text { totais } \\
(\mathrm{CV}=\mathbf{6 , 2 5 \%})\end{array}$} & \multicolumn{2}{|c|}{$\begin{array}{c}\beta \text {-caroteno } \\
(\mathrm{CV}=6,74 \%)\end{array}$} & \multicolumn{2}{|c|}{$\begin{array}{c}\text { Licopeno } \\
(\mathrm{CV}=\mathbf{6 , 7 0 \%})\end{array}$} & \multicolumn{2}{|c|}{$\begin{array}{c}\text { Vitamina } A \\
(C V=6,74 \%)\end{array}$} \\
\hline & & Freezer & $\begin{array}{l}\mathbf{N} \text { liq. }+ \\
\text { freezer }\end{array}$ & Freezer & $\begin{array}{l}\mathbf{N} \text { liq. }+ \\
\text { freezer }\end{array}$ & Freezer & $\begin{array}{l}\mathbf{N} \text { liq. }+ \\
\text { freezer }\end{array}$ & Freezer & $\begin{array}{l}\mathbf{N} \text { liq. }+ \\
\text { freezer }\end{array}$ \\
\hline \multicolumn{2}{|c|}{ Coleta na árvore } & $\begin{array}{c}6,78 \\
\mathrm{Ca}\end{array}$ & $\begin{array}{c}6,75 \\
\mathrm{Ca}\end{array}$ & $\underset{\mathrm{Ca}}{6,75}$ & $\underset{\mathrm{Ca}}{6,26}$ & $\begin{array}{c}1,32 \\
\mathrm{Ba}\end{array}$ & $\begin{array}{c}1,12 \\
\mathrm{Ca}\end{array}$ & $\begin{array}{c}112 \\
\mathrm{Ca}\end{array}$ & $\begin{array}{c}104 \\
\mathrm{Ca}\end{array}$ \\
\hline \multicolumn{2}{|c|}{$\begin{array}{l}\text { Coleta no chão após } \\
\text { queda natural }\end{array}$} & $\begin{array}{c}8,37 \\
\mathrm{Ba}\end{array}$ & $\begin{array}{c}9,39 \\
\mathrm{Ba}\end{array}$ & $\begin{array}{l}7,8 \\
\mathrm{Ba}\end{array}$ & $\begin{array}{c}8,56 \\
\mathrm{Ba}\end{array}$ & $\begin{array}{c}1,42 \\
\mathrm{Ba}\end{array}$ & $\begin{array}{c}1,47 \\
\mathrm{Ba}\end{array}$ & $\begin{array}{l}130 \\
\mathrm{Ba}\end{array}$ & $\begin{array}{l}142 \\
\mathrm{Ba}\end{array}$ \\
\hline \multicolumn{2}{|c|}{$\begin{array}{l}\text { Coleta após queda } \\
\text { natural + } \\
\text { três dias em condição } \\
\text { ambiente }\end{array}$} & $\begin{array}{c}11,34 \\
\mathrm{Aa}\end{array}$ & $\begin{array}{c}11,07 \\
\text { Aa }\end{array}$ & $\begin{array}{l}9,7 \\
\mathrm{Ab}\end{array}$ & $\begin{array}{c}11,4 \\
\mathrm{Aa}\end{array}$ & $\begin{array}{l}1,74 \\
\mathrm{~A} b\end{array}$ & $\begin{array}{c}2,08 \\
\mathrm{Aa}\end{array}$ & $\begin{array}{c}161 \\
\mathrm{Ab}\end{array}$ & $\begin{array}{c}190 \\
\mathrm{Aa}\end{array}$ \\
\hline
\end{tabular}

Médias seguidas pela mesma letra, maiúsculas nas colunas e minúsculas nas linhas, indicam que o estádio de maturação dos frutos e tipo de congelamento, respectivamente, não diferem estatisticamente, pelo teste de Tukey $(p<0,05)$. $(\mathrm{N}=$ nitrogênio).

encontrados em Lycopersicon esculentum var. Santa Cruz (Niizu \& Rodriguez-Amaya, 2004). Subtraindo-se a soma dos valores de $\beta$ caroteno e licopeno dos valores de carotenóides totais, verifica-se que outros carotenóides, além dos avaliados no presente experimento, devem contribuir para a coloração da polpa de pequi, confirmando as observações de Ramos et al. (2001) e AzevedoMeleiro \& Rodriguez-Amaya (2004) de que os principais carotenóides do pequi são a violaxantina, luteína e zeaxantina.

No pequi, além do tamanho do putâmen, a espessura e a coloração da polpa são utilizadas como critério de seleção pelos consumidores. Os carotenóides são considerados os principais pigmentos responsáveis pela coloração da polpa; putamens mais alaranjados são, geralmente, os preferidos pelos consumidores. Considerando esse fato e somando-se a ele as observações de que o acúmulo de carotenóides na polpa do pequi continuou após a retirada dos frutos da planta e mesmo após a queda natural, o tempo normalmente gasto da coleta ao consumo do fruto é favorável à intensificação na coloração da polpa.

Os teores médios de vitamina A (Tabela 2) encontrados na polpa variaram de 104 x $10^{3}$ U.I. e $190 \times 10^{3}$ U.I. e estão na faixa dos observados por Vilela (1998), 192,7 x $10^{3}$ U.I., e Carvalho \& Burger (1960), 200 x $10^{3}$ U.I., porém Ramos et al. (2001) determinaram um teor de vitamina A de 4.939 UI/100g na polpa do pequi. A discrepância entre os resultados pode estar relacionada aos aspectos metodológicos. Em geral, a determinação dos valores de vitamina $\mathrm{A}$ disponíveis na literatura é baseada no teor de $\beta$-caroteno, cuja determinação utiliza metodologia convencional baseada na espectrofotometria. No entanto, as análises de Ramos et al. (2001) foram realizadas por cromatografia, que permite uma identificação mais segura dos carotenóides. Sendo assim, é provável que os valores de $\beta$-caroteno e vitamina $A$ em polpa de pequi encontrados na literatura estejam superestimados. Apesar disso, o fruto de pequizeiro pode ser considerado uma fonte potencial de vitamina A, pois a quantidade diária exigida na dieta pela OMS é de 4.500 U.I.

$\mathrm{O}$ teor de vitamina A na polpa aumentou com o avanço no estádio de maturação dos frutos. No tratamento em que os frutos foram coletados no chão, três dias após a queda natural, o congelamento rápido promoveu maiores valores de vitamina $\mathrm{A}$, fato este associado aos maiores teores de carotenóides observados no mesmo tratamento.

Teor de pectina total (Tabela 3)- O teor de pectina total na polpa de pequi variou de 178,8 U/g a 197,3 U/g, não apresentando uma tendência de variação definida em função do grau de maturação dos frutos, exceto nos frutos coletados no chão três dias após a queda natural, em que o teor de pectina total foi menor $(p>0,05)$ quando a polpa foi submetida ao congelamento rápido ( $\mathrm{N}$ líquido, antes do armazenamento em freezer). Comportamento semelhante foi observado por Pimenta et al. (2000), que não observaram relação entre o teor de pectina total e o grau de maturação em grãos de café. Em outras espécies, como abacaxi, fruta-de-lobo e bacuri, os teores de pectina total diminuem continuamente no decorrer do processo de maturação dos frutos (Vilas Boas, 1998; Corrêa et al., 2000; Teixeira et al., 2001, respectivamente).

As pectinas em frutos encontram-se em diferentes formas. A

TABELA 3 - Efeito do estádio de maturação dos frutos sobre a atividade das enzimas poligalacturonases (PG) (U/g), pectinametilesterases (PME) (U/g) e teor de pectina total (mg de ácido galacturônico/100g).

\begin{tabular}{|c|c|c|c|c|c|c|c|}
\hline \multirow{2}{*}{$\begin{array}{c}\text { Estádio de } \\
\text { maturação dos } \\
\text { frutos }\end{array}$} & \multirow{2}{*}{$\begin{array}{c}\begin{array}{c}\text { Parâmetros } \\
\text { avaliados }\end{array} \\
\begin{array}{c}\text { Tipo de } \\
\text { congelamento }\end{array}\end{array}$} & \multicolumn{2}{|c|}{$\begin{array}{c}\text { PG } \\
(\mathrm{CV}=\mathbf{2 , 4 9 \% )}\end{array}$} & \multicolumn{2}{|c|}{ PME } & \multicolumn{2}{|c|}{ Pectina total } \\
\hline & & Freezer & $\begin{array}{l}\mathbf{N} \text { liq. }+ \\
\text { freezer }\end{array}$ & Freezer & $\begin{array}{l}\mathbf{N} \text { liq. }+ \\
\text { freezer }\end{array}$ & Freezer & $\begin{array}{l}\mathbf{N} \text { liq. }+ \\
\text { freezer }\end{array}$ \\
\hline Coleta na árvore & & $\begin{array}{c}45,46 \\
\mathrm{Cb}\end{array}$ & $\begin{array}{c}49,41 \\
\mathrm{Ca}\end{array}$ & ND & ND & $\begin{array}{c}193,3 \\
\text { Aa }\end{array}$ & $\begin{array}{c}195,2 \\
\mathrm{Aa}\end{array}$ \\
\hline $\begin{array}{l}\text { Coleta no chão } \\
\text { após queda natural }\end{array}$ & & $\begin{array}{c}58,65 \\
\mathrm{Ba}\end{array}$ & $\begin{array}{c}51,45 \\
\mathrm{Bb}\end{array}$ & ND & ND & $\begin{array}{c}182,0 \\
\mathrm{Aa}\end{array}$ & $\begin{array}{c}197,3 \\
\text { Aa }\end{array}$ \\
\hline $\begin{array}{l}\text { Coleta após queda n } \\
\text { três dias em condiçãa }\end{array}$ & $\begin{array}{l}\text { Iral + } \\
\text { imbiente }\end{array}$ & $\begin{array}{c}64,80 \\
\text { Aa }\end{array}$ & $\begin{array}{c}55,69 \\
\mathrm{Ab}\end{array}$ & ND & ND & $\begin{array}{c}194,4 \\
\mathrm{Aa}\end{array}$ & $\begin{array}{c}178,8 \\
\mathrm{Bb}\end{array}$ \\
\hline
\end{tabular}

Médias seguidas pela mesma letra, maiúsculas nas colunas e minúsculas nas linhas, indicam que o estádio de maturação dos frutos e tipo de congelamento, respectivamente, não diferem estatisticamente, pelo teste de Tukey $(\mathrm{p}<0,05)$. $(\mathrm{N}=$ nitrogênio $)$. ND= Não detectada. 
protopectina é a forma insolúvel em água e, no decorrer do amadurecimento, sofre transformação para pectina que, por ação enzimática, sofre solubilização até a degradação total, quando o fruto está maduro (Chitarra \& Chitarra, 1990). No presente trabalho, foi avaliado apenas o teor de pectina total e não a solúvel. No entanto, o aumento na atividade de enzimas que as hidrolisam durante a maturação de frutos, pode indicar aumento na solubilização.

Atividade da PG e PME (Tabela 3) - No mesocarpo interno de pequi, a atividade da $\mathrm{PG}$ foi baixa (45-64 U/g) e não foi observada atividade da PME. Os valores de atividade da PG na polpa de pequi estão na faixa dos encontrados em polpa de bacuri (Teixeira et al., 2001), mas muito aquém da observada em grãos de café em processo de maturação, nos quais a atividade alcançou 218,03 U/g (Pimenta et al., 2000) e abacaxi, no qual a atividade chegou a 765,53 U/g (Thé et al., 2001). A atividade da PG foi significantemente afetada pelo grau de maturação dos frutos e aumentou gradativamente com este, mas em maior magnitude na polpa submetida a congelamento lento (freezer), quando comparada à polpa submetida a congelamento rápido ( $\mathrm{N}$ líquido depois freezer). Esses resultados concordam com a observação de alguns autores, de que, em frutos imaturos, há ausência da PG, havendo seu aparecimento próximo ao início do amadurecimento, e sugere que ela esteja implicada na solubilidade de pectinas. A redução nas substâncias pécticas explica, em parte, a redução na firmeza da polpa. A maior atividade da PG na polpa de pequi em frutos mantidos três dias em temperatura ambiente, após a queda natural, pode sugerir que esta enzima contribui para a mudança de textura da polpa no período que vai da coleta dos frutos até o consumo. Diferentemente do pequi, na polpa de bacuri, o aumento na atividade da PG com o avanço no estádio de maturação dos frutos está associada à redução no teor de pectina total (Teixeira et al., 2001).

As substâncias pécticas, derivadas do ácido poligalacturônico, encontram-se, principalmente, depositadas na parede celular, atuando como material cimentante, sendo responsáveis pelas mudanças de textura dos frutos (Chitarra \& Chitarra, 1990). A PG catalisa a hidrólise de ligações $\alpha-1,4$ entre dois resíduos adjacentes de ácido galacturônico (Seymour et al., 1987). A baixa atividade da PG na polpa de pequi sugere que esta enzima não deve ser a principal responsável pela solubilidade das pectinas durante o processo de amaciamento dos frutos dessa espécie. Por outro lado, cabe ressaltar que, mesmo níveis muito baixos de PG, são suficientes para catalisar a hidrólise das pectinas. Reduções de $80 \%$ na atividade da $\mathrm{PG}$ em frutos de tomate apresentaram pouco efeito sobre a redução na hidrólise de pectinas (Hadfield \& Bennett, 1998), indicando que, em algumas espécies, a PG pode estar presente em excesso.
A PME promove a desmetilação de resíduos de ácido metilgalacturônico (Seymour et al., 1987). A ausência de atividade da PME na polpa de pequi sugere que a ação desta enzima tem pouco ou nenhum significado para as mudanças que ocorrem na textura da polpa durante o amadurecimento, ou que as pectinas da parede celular do pequi apresentam baixo grau de metilação. De acordo com Cheftel \& Cheftel (1992), o correto seria denominar pectinas somente as cadeias de ácido galacturônicos $100 \%$ metiladas, e ácidos pectínicos as cadeias poligalacturônicas com grau de metilação inferior. Sendo assim, pode-se dizer que, na polpa do pequi, existem apenas ácidos pectínicos. Na prática, emprega-se o termo pectinas tanto para os ácidos pectínicos como para as pectinas propriamente ditas. Em polpa de bacuri (Teixeira et al., 2001) e manga “Tommy Atkins" (Evangelista et al., 2002), também não foi detectada atividade da PME. Em abacaxi, a atividade da PME não variou com o tipo de congelamento, mas com o estádio de maturação dos frutos (Thé et al., 2001).

Teores de celulose e hemicelulose (Tabela 4)- Outros componentes da parede celular, além das pectinas, que também podem ser responsabilizados pelo amaciamento dos frutos durante a maturação, são a celulose e a hemicelulose. $O$ teor de celulose não variou com o tipo de congelamento; foi maior nos frutos coletados no chão após a queda natural e decresceu nos frutos coletados no chão, três dias após a queda natural. A redução no teor de celulose após a queda natural dos frutos pode estar associada à maior atividade de outras hidrolases de parede celular, além da PG e PME. Além da atividade da PG, a atividade da celulase e da $\beta$-galactosidase aumentou com o amadurecimento de manga (Evangelista et al., 2002) e melão (Ranwala et al. 1992), respectivamente, e esse aumento estava associado ao aumento da solubilidade e despolimerização de pectinas.

A fração hemicelulósica não apresentou interação entre estádio de maturação dos frutos e tipo de congelamento. Na polpa de bacuri, a fração hemicelulósica não variou com o estádio de maturação dos frutos, mas foi observada uma redução de $28,23 \%$ nessa fração após 16 dias de armazenamento dos frutos (Teixeira et al. 2001). Essa característica, juntamente com a redução nas substâncias pécticas, foi a principal responsável pelo amaciamento da polpa nessa espécie.

A hemicelulose e a celulose desempenham importantes funções estruturais, interagindo com as substâncias pécticas. As observações de que outras hidrolases, além da PG e da PME, participam do amaciamento da polpa de frutos durante a maturação, somadas à baixa atividade da PG e ausência de atividade da PME observadas no presente estudo, são indicativos de que estas enzimas não são as principais responsáveis pelo amaciamento da polpa de pequi durante o amadurecimento. A redução no teor de celulose

Tabela 4 - Efeito do estádio de maturação dos frutos sobre os teores de celulose (\%), hemicelulose (\%),cálcio ligado à parede (\%) e cálcio total $(\%)$

\begin{tabular}{|c|c|c|c|c|c|c|c|c|c|}
\hline \multirow{2}{*}{$\begin{array}{c}\text { Estádio de } \\
\text { maturação } \\
\text { dos frutos }\end{array}$} & \multirow{2}{*}{\begin{tabular}{|c|}
$\begin{array}{l}\text { Parâmetros } \\
\text { avaliados }\end{array}$ \\
$\begin{array}{c}\text { Tipo de } \\
\text { congelamento }\end{array}$
\end{tabular}} & \multicolumn{2}{|c|}{ Celulose } & \multicolumn{2}{|c|}{ Hemicelulose } & \multicolumn{2}{|c|}{$\begin{array}{l}\text { Cálcio ligado à } \\
\text { parede }\end{array}$} & \multicolumn{2}{|c|}{ Cálcio total } \\
\hline & & Freezer & $\begin{array}{l}\mathbf{N} \text { liq. }+ \\
\text { freezer }\end{array}$ & Freezer & $\begin{array}{l}\mathbf{N} \text { liq. }+ \\
\text { freezer }\end{array}$ & Freezer & $\begin{array}{l}\mathbf{N} \text { liq. + } \\
\text { freezer }\end{array}$ & Freezer & $\begin{array}{l}\mathbf{N} \text { liq. }+ \\
\text { freezer }\end{array}$ \\
\hline \multicolumn{2}{|c|}{ Coleta na árvore } & $\begin{array}{c}33,4 \\
\text { Aa }\end{array}$ & $\begin{array}{c}32,1 \\
\text { Aa }\end{array}$ & $\begin{array}{l}8,9 \\
\mathrm{Aa}\end{array}$ & $\begin{array}{l}9,0 \\
\text { Aa }\end{array}$ & $\begin{array}{c}0,14 \\
\mathrm{Aa}\end{array}$ & $\begin{array}{c}0,13 \\
\mathrm{Aa}\end{array}$ & $\begin{array}{c}0,09 \\
\mathrm{Aa}\end{array}$ & $\begin{array}{c}0,09 \\
\mathrm{Aa}\end{array}$ \\
\hline \multicolumn{2}{|c|}{$\begin{array}{l}\text { Coleta no chão } \\
\text { Após queda natural }\end{array}$} & $\begin{array}{c}35,9 \\
\text { Aa }\end{array}$ & $\begin{array}{c}34,1 \\
\text { Aa }\end{array}$ & $\begin{array}{l}9,8 \\
\text { Aa }\end{array}$ & $\begin{array}{l}9,2 \\
\text { Aa }\end{array}$ & $\begin{array}{c}0,10 \\
\mathrm{Aa}\end{array}$ & $\begin{array}{c}0,12 \\
\mathrm{Aa}\end{array}$ & $\begin{array}{c}0,09 \\
\text { Aa }\end{array}$ & $\begin{array}{c}0,10 \\
\mathrm{Aa}\end{array}$ \\
\hline \multicolumn{2}{|c|}{$\begin{array}{l}\text { Coleta após queda natural + } \\
\text { três dias em condição } \\
\text { ambiente }\end{array}$} & $\underset{\mathrm{Bb}}{29,2}$ & $\begin{array}{c}29,9 \\
\mathrm{Bb}\end{array}$ & $\begin{array}{l}9,2 \\
\text { Aa }\end{array}$ & $\begin{array}{l}9,5 \\
\mathrm{Ab}\end{array}$ & $\begin{array}{c}0,12 \\
\mathrm{Aa}\end{array}$ & $\begin{array}{c}0,12 \\
\text { Aa }\end{array}$ & $\begin{array}{c}0,11 \\
\text { Aa }\end{array}$ & $\begin{array}{c}0,11 \\
\text { Aa }\end{array}$ \\
\hline
\end{tabular}

Médias seguidas pela mesma letra, maiúsculas nas colunas e minúsculas nas linhas, indicam que o estádio de maturação dos frutos e tipo de congelamento, respectivamente, não diferem estatisticamente, pelo teste de Tukey $(\mathrm{p}<0,05)$. $(\mathrm{N}=$ nitrogênio $)$. 
com o avanço no estádio de maturação dos frutos indica que outras frações da parede celular, além das pectinas, devem participar do amaciamento da polpa de pequi.

Cálcio total e cálcio ligado (Tabela 4) - Os teores médios de cálcio ligado à parede celular e de cálcio total variaram de 0,10 a 0,14 e de 0,09 a $0,11 \%$, respectivamente, e não diferiram estatisticamente $(0,05 \%)$ entre os estádios de maturação dos frutos e tipo de congelamento. Valores de $0,05 \%$ e $0,06 \%$ de cálcio em polpa de pequi foram observados por Araújo (1995) e Almeida \& Silva (1994).

$\mathrm{O}$ cálcio na parede celular, ao ligar-se covalentemente às pectinas, dá origem ao pectato de cálcio, restringindo a ação da PME e PG e, conseqüentemente, retardando o amaciamento de frutos (Salunkhe et al., 1991). Segundo Evangelista et al. (2002), a ação da PME em promover sítios de ligação para o cálcio é, sem dúvida, importante para a concentração deste íon na parede celular e na lamela média. A ausência de atividade da PME no presente trabalho pode ter contribuído para a não-alteração nos teores de cálcio ligado com o estádio de maturação de pequi. Scalon (1996) observou aumento no teor de cálcio ligado na parede celular em morangos associado à maior atividade da PME. Pulverizações ou imersões de frutos em soluções de cloreto de cálcio retardam o amaciamento e senescência em função do aumento do $\mathrm{Ca}^{++}$ligado à $\mathrm{PC}$ (Scalon, 1996). Pode-se inferir, portanto, que o pequi não responderia a tratamento com cálcio com o objetivo de melhorar a consistência da polpa. Essa característica é de grande importância quando da preparação de conserva, utilizando apenas a polpa (ao invés do putâmen inteiro), muito utilizada no processamento atual de pequi. Nesse tipo de processamento, a polpa deve ser retirada de frutos colhidos imediatamente após a queda natural. Os demais frutos são descartados e utilizados para outros fins, por apresentarem polpa de consistência reduzida.

Por outro lado, uma redução no teor de cálcio ligado à parede celular, associada ao avanço no estádio de maturação dos frutos, foi observada por Teixeira et al. (2001) em polpa de bacuri. Esse fato foi atribuído à desestabilização do complexo pectina-proteína da lamela média, que ocorre durante a maturação, devido à maior atuação das enzimas relacionadas ao processo de amaciamento e amolecimento dos frutos.

\section{CONCLUSÕES}

1) Embora o pequi seja considerado maduro logo que cai da árvore, o processo de maturação continua após a queda natural.

2) Frutos coletados na árvore mostraram-se nutricionalmente inferiores aos frutos coletados após a queda natural e aqueles mantidos três dias em condição ambiente após a queda natural.

3) Embora o avanço no estádio de maturação dos frutos reduza a consistência da polpa, os maiores valores nos teores de proteínas, lipídios, carotenóides totais, $\beta$-caroteno, licopeno e vitamina $\mathrm{A}$, observados nos frutos coletados após a queda natural e mantidos três dias em condição ambiente, indicam que o tempo de três dias entre a coleta e o consumo favorece a qualidade nutricional da polpa de pequi.

4) A estabilidade dos pigmentos e, conseqüentemente, da vitamina A foi favorecida pelo congelamento rápido.

5) Embora os componentes da parede celular, associados à textura da polpa, exceto atividade da PG e o teor de celulose, não tenham variado com o estádio de maturação dos frutos, é possível que estes sejam influenciados pelo tempo de armazenamento póscolheita, como observado em frutos de outras espécies, o que deve ser fonte para outros estudos.

\section{AGRADECIMENTOS}

Ao $\mathrm{CNPq}$, pela concessão do auxílio à pesquisa, e à FAPEMIG, pela concessão de bolsas.

\section{REFERÊNCIAS}

ALMEIDA, S.P.; SILVA, J.A. Piqui e buriti: importância alimentar para a população dos cerrados. Planaltina: EMBRAPA-CPAC, 1994. 38p. (Documentos, 54).

ALVES, R. Novidades do pequi: Estado de Minas. Belo Horizonte: Agropecuário, 2004. p.6.

ARAÚJO, F.D. A review of Caryocar brasiliense (Caryocaraceae) $\mathrm{Na}$ economical valuable species of the central Brasilian Cerrados. Economic Botany, Bronx, v.49, n.1, p.40-48, 1995.

ARAÚJO, F.D. The Ecology, etnobotany and manegment of Caryocar brasiliense Camb. around Montes Claros, MG, Brasil. 1994. $174 \mathrm{f}$. Tese (Doutorado em Ecologia) - University of Oxford, Oxford, 1994

AOAC- ASSOCIATION OF OFFICIAL AND AGRICULTURAL CHEMISTS. Official methods of analysis. $10^{\text {th }} \mathrm{ed}$. Washington, 1965. p.744-745.

AZEVEDO-MELEIRO, C.H.; RODRIGUEZ-AMAYA, D.B. Confirmation of the identity of the carotenoids of tropical fruits by HPLC-DAD and HPLC-MS. Journal of Food Composition and Analysis, San Diego, v.117, p.385-396, 2004.

BITTER, T.; MUIR, H.M. A modified uronic acid carbazole reaction. Analytical Biochemistry, New York, v.34, p.330-334, 1962.

BRUMMELL, D.A.; LABAVITCH, J.M. Effect of antisense supression of endopolygalacturonase activity on polyuronide molecular weight in ripening tomato fruit and in fruit homogenates. Plant Physiology, Washington, v.115, p.715-725, 1997.

CARVALHO, M. C.; BURGER, O. N. Contribuição ao estudo do pequi de Brasília. Brasília: SPS, 1960. 15p. (Coleção Estudo e Pesquisa Alimentar, 50).

CAVALCANTE, M.L. Composição de carotenóides e valor de vitamina A em pitanga (Eugenia uniflora) e acerola (Malpighia glabra). 1991. 90 f.Dissertação (Mestrado) - Universidade Federal do Rio de Janeiro, Rio de Janeiro, 1991.

CHEFTEL, J.C.; CHEFTEL, H. Introducción a la bioquímica y tecnologia de los alimentos. Zagaroza: Editorial Acriba, 1992. v.1,333p.

CHEFTEL, J.C.; CHEFTEL, H.; BESANCON, P. Métodos de conservacion. In: CHEFTEL, J.C.; CHEFTEL, H. Introduction a la bioquimica y tecnologia de los alimentos. Zagarosa: Acribia, 1989. v.2, cap.7, p.175-299.

CHITARRA, A.B.; CHITARRA, M.I.F. Pós-colheita de frutos e hortaliças: fisiologia e manuseio. Lavras. Ed. Gráfica Nagy, 1990. 293p. 1990.

CORRÊA, A. D.; ABREU, C. M. P.; SANTOS, C. D.; RIBEIRO, L. J. Constituintes químicos da fruta-de-lobo (Solanum lycocarpum St. Hil.) durante a maturação. Ciência e Agrotecnologia, Lavras, v.24, n.1, p. 130-135, 2000.

DISCHE, E. Color reactions of carbohydratees. In: WHISTLER, R. L.; WOLFROM, M. L. (Ed.). Methods in carbohydrate chemistry. New York: Academic, 1962. v. 1, p.467-512, 1962.

EVANGELISTA, R. M.; CHITARRA, A. B.; CHITARRA, M. I. F. Mudanças na ultra-estrutura da parede celular de mangas 'Tommy Atkins' Tratadas com cloreto de cálcio na pré-colheita. Revista Brasileira de Fruticultura, Jaboticabal, v.24, n.1, p.254257, Abril, 2002.

FERREIRA, F.R.; BIANCO, S.; DURIGAN, J.F.; BELINGIERI, P.A.; Caracterização física e química de frutos maduros de pequi. In: CONGRESSO BRASILEIRO DE FRUTICULTURA, 9., 1987. Campinas. Anais... Campinas: Sociedade Brasileira de Fruticultura, 1987. v.2, p.643-646.

FRANCO, G. Nutrição: texto básico e tabela de composição química de alimentos. _. In: Composição química dos alimentos e valor energético. 6.ed. In. Rio de Janeiro: Atheneu, 1982. p.180193. 
GODOY, H.T. Estudos de carotenóides e pró-vitamina A em alimentos 1993. Tese (Doutorado em Ciências de Alimentos) - Faculdade de Engenharia de Alimentos, Universidade Estadual de Campinas, Campinas, 1993.

GOLDSCHMIDT, E. E. Pigments changes associated with fruit maturation and their control. In: THIMANN, K.V. Senescence in plants. Boca Raton: CRC Press, 1980.677p.

HADFIELD, K.A.; BENNETT, A.B. Polygalacturonases: many genes in search of a function. Plant Physiology, Washington, v.117, p.337-343, 1998.

NAGATA, M.; YAMASHITA, I. Simple method for simultaneous determination of chlorophyll and carotenoids in tomato fruit. Nippon Shokuhin Kogyo Gakkaishi, Tokyo, v. 39, n. 10, p. $925-$ 928, 1992.

NELSON, N.A. A photometric adaptation of Somogyi method for the determination of glucose. Journal of Biological Chemistry, Baltimore, v.15, n.1, p.375-380, 1944.

NIIZU, P.Y.; RODRIGUEZ-AMAYA, D.B. New data on the carotenoid composition of raw salad vegetables. Journal of Food Composition and Analysis, San Diego, v.18, n.8, p.739-749, 2004

PIMENTA, C.J.; CHAGAS, S.J.R.; COSTA, L. Pectinas e enzimas pectinolíticas em café (Coffea arabica L.) colhido em quatro estádios de maturação. Ciência Agrotecnológica, Lavras, v.24, n.4, p.1079-183, 2000.

PRESSEY, R.; AVANTS, J.K. Separation and characterization of the exopoligalacturonase and endopoligalacturonase from peaches. Plant Physiology, Washington, v.44, n.12, p.1717-1723, 1969.

RAMOS, M.I.L. Desidratação do piqui (Caryocar brasiliense, Camb.): avaliação do processo através dos teores de carotenóides totais. 1987. 116 f. Dissertação (Mestrado)Faculdade de Ciências Farmacêuticas, Universidade de São Paulo, 1987.

RAMOS, M.I.L.; UMAKI, M.C.S.; HIANE, P.A.; RAMOS FILHO, M.M. Efeito do cozimento convencional sobre os carotenóides pró-vitamínicos "A" da polpa do piqui (Caryocar brasiliense). Boletim CEPPA, Curitiba, v.19, n.1, p.23-32, 2001.

RANWALA, A. P.; SUEMATSU, C.; MASUDA, H. The role of $\beta$ galactosidases in the modification of cell wall components during muskmelon ripening. Plant Physiology, Washington, v.100, n.3, p.1318-1325, 1992 .
RATNER, A.; GOREN, R.; MONSELINE, S.P. Activity of pectin esterase and cellulase in the abcission zone of citrus leaf explants. Plant Physiology, Washington, v.44, p.1717-1723, 1969.

SALUNKHE, D.K.; BOLIN, H.R.; REDDY, N.R. Storage, processing and nutritional quality of fruits and vegetables. Boca Raton: CRC Press, 1991.323p.

SARRUGE, J.R.; HAAG, H.P. Análise química de plantas. Piracicaba: ESALQ, 1974. 56p.

SCALON, S. P. Q. Qualidade do morango: Efeito do $\mathrm{CaCl}_{2}$ sobre a parede celular e níveis residuais de Benomil. 1996. 105f. Tese (Doutorado) - Universidade Federal de Lavras. Lavras, 1996.

SEYMOUR, G. B.; HARDING, S. E.; TAYLOR, A. J.; HOBSON, G. E.; TUCKER, G. A. Polyuronide solubilisation during ripening of normal and mutant tomato fruit. Phytochemistry, Kidlington, v.26, n.3, p.1871-1875, 1987 .

TEIXEIRA, G. H.A.; DURIGAN, J. F.; ALVES, R. E.; FILGUEIRAS, H. A. C.; MOURA, C. F. H. Frutos do bacurizeiro (Platonia insignis Mart.): Caracterização, qualidade e conservação. I. Análises químicas e bioquímicas. Revista Brasileira de Fruticultura, Jaboticabal, v.23, n.1, p.116-120, 2001.

THÉ, P. M. P.; CARVALHO, V. D. C.; ABREU, C. M. P.; NUNES, R. P.; PINTO, N. A. V. D. Modificações na atividade enzimática em abacaxi "Smooth Cayenne" em função da temperatura de armazenamento e do estádio de maturação. Ciência e Agrotecnologia, Lavras, v.25, n.2, p.364-370, 2001.

VILAS BOAS, E. V. de B. Modificações pós-colheita durante a maturação de tomates normais e suas correspondentes versões quase isogênicas heterozigotas no alelo alcobaça. 1998. 103f. Tese (Doutorado em Ciências dos Alimentos) - Universidade Federal de Lavras, Lavras, 1998.

VILELA, G. F. Variações em populações naturais de Caryocar brasiliense Camb. (Caryocaraceae): fenológicas, genéticas e de valores nutricionais de frutos. 1998. 88f. Dissertação (Mestrado em Engenharia Florestal) - Universidade Federal de Lavras. , Lavras, 1998. 